\title{
EFFECT OF HYPERBARIC OXYGEN THERAPY ON OSSEOINTEGRATION OF DENTAL IMPLANT RETAIN MANDIBULAR OVERDENTURES WITH BISPHOSPHONATE TREATED PATIENTS
}

\author{
Nasser H. Shaheen* and Essam I. Elkhatat**
}

\begin{abstract}
Aim of the study: This study aimed to evaluate the effect of hyperbaric oxygen therapy on success rate of implants used to retain mandibular overdentures and possibility of osteonecrosis of the jaw in Bisphosphonate treated osteoporotic patients.

Materials and methods: Eight systemic free patients were selected as control group (CG) and eight osteoporotic patients treating with Bisphosphonate drugs orally more than two years were selected as study group (SG). For both groups, patients received mandibular implant retained overdentures with locator anchors following two stage surgical protocol. Patients of study group were received Hyperbaric oxygen thereby (HBO) after the first stage surgery, while those of control group were not received (HBO). Peri-implant marginal bone height and density were evaluated at six months (T6), twelve months (T12) after insertion using Cone Beam Computed Tomography (CBCT).
\end{abstract}

Results: No failure of dental implants were recorded with $100 \%$ cumulative survival rates for both groups. Both groups showed increase in bone density and decrease in marginal bone height through a period of one year follow-up. However, the group that received HBO therapy showed less marginal bone loss and more increase in bone density than the control group.

Conclusion: Hyperbaric oxygen therapy is valuable and effective treatment for osteoporotic treated Bisphosphonate patients receiving implant retained mandibular overdentures as it eliminate the possibility of Bisphosphonate associated osteonecrosis of the jaw (BONJ), reduces bone loss and increase bone density around dental implant resulting in normal survival rate.

KEYWORDS: Hyperbaric oxygen, Bisphosphonate, implant, overdenture.

* Associate Professor, Department of Removable Prosthodontics, College of Oral and Dental Surgery, Misr University for Science and Technology, Egypt. Associate Professor, Prosthetic Dental Sciences Department, Al-Farabi Collage, Saudi Arabia.

** Assistant Professor, Preventive Dental Sciences Department, Al-Farabi Collage, Saudi Arabia. 


\section{INTRODUCTION}

Normally, the skeleton carries out several functions as support, mobility, and protection for vital organs and acting as reservoir for calcium and phosphate. The skeleton remain in a dynamic equilibrium between osteoblastic and osteoclastic activity for bone remodeling procedure. This bone remodeling procedure occurs in a regular manor, resulting in minimal change in the amount of bone. At the end of twenties, individual reaches maximum bone mass then the balance between bone formation and resorption changes with relative increases in bone resorption leading to bone loss most of bone loss after the age of 65 is cortical bone loss; however, bone loss after menopause is mainly trabecular bone loss.

Osteoporosis is a systemic skeletal disease characterized by low bone mass and microarchitectural deterioration, with a consequent increase in bone fragility and susceptibility to fracture, particularly of the vertebral body, distal forearm and proximal femur in postmenopausal women ${ }^{[1]}$. Reduced bone strength results from a loss of bone tissue, a consequence of imbalances between bone formation and resorption, as well as a subsequent deterioration in skeletal microarchitecture ${ }^{[2]}$. Osteoporosis is classified into primary and secondary osteoporosis based on the precipitating factors. Recently, many authors supporting the idea that, there is a growing acknowledgement for the involvement of the immune system in the pathogenesis of osteoporosis precipitating the emergence of the field of osteoimmunology ${ }^{[3]}$. Bisphosphonate group of drugs are pyrophosphate analogues. They have a high affinity to bone and are taken up by osteoclasts during natural bone resorption. Bisphosphonates work by acting on osteoclast function to reduce bone resorption. They are important in treating many conditions such as osteoporosis, Paget's disease, hypercalcaemia, osteogenesis imperfecta, skeletal defects associated with metastatic cancer, primary hyperparathyroidism and malignancy. Despite the bisphosphonates have an excellent safety record, there have been case reports of Bisphosphonate associated osteonecrosis of the jaw (BONJ) particularly after surgical procedures,) that might be caused by long-term use. Thus, completely edentulous patients who are receiving oral Bisphosphonate for the treatment of osteoporosis are not allowed to have implants ${ }^{[4-9]}$.

Edentulism is considered as a debilitating handicap condition duo to difficulties in denture retention and stability ${ }^{[10]}$. Particularly in case of mandibular denture as reduced supporting area, motion of the tongue and continuous alveolar ridge resorption. In fact, the most reliable management which provide both retention and stability of the prosthesis for edentulous mandible is inserting of two implants in the canine region, either splinted or not ${ }^{[10]}$. Several types of anchors can be used to retain the overdentures to the implants, such as locators, balls, bar attachments and magnets ${ }^{[1]}$. Locator attachments are flexible anchor, self-aligning, have different degrees of retention values, have some built-in angulation compensation, can be used successfully with limited inter-arch distance. In addition, repair and replacement are simple and easy.

Hyperbaric oxygen (HBO) therapy improve the success of osseointegration, as it improves bone maturation ${ }^{[12.13]}$. HBO protocol is the inhalation of $100 \%$ pure oxygen inside a hyperbaric chamber that is pressurized to greater than 1 atmosphere absolute (ATA) till 3 ATA. The duration of HBO session is ranged from 90 to $120^{[14]}$. HBO therapy results in increases dissolved oxygen in the blood and results in high partial pressure of oxygen $(\mathrm{PaO} 2)$ in body tissues. The increase of oxygen tension in regenerating tissue mimic the growth of new blood vessels, promotes collagen and adenosine-triphosphate (ATP) synthesis, increasing osteoblastic and osteoclastic activity ${ }^{[15,16]}$ causes cellular differentiation to osseous tissue ${ }^{[17]}$, so improving osteogenesis, bone 
remodeling and healing ${ }^{[18,19]}$, which result in more bone formation ${ }^{[20]}$.

HBO therapy affect several conditions as osteoporosis, improved bone formation in patients treated with Bisphosphonate, gas gangrene, necrotizing soft-tissue infections, acute ischemia's, exceptional blood loss anemia, refractory osteomyelitis, compromised skin grafts, thermal burns and intracranial abscesses and involved in diabetes ${ }^{[21,22]}$. It is interestingly, to know that HBO also affect management of many restorative materials, according to Hossam et. al. in $2007,2009^{[23,24]}$

From understanding the mechanism and physiology of Hyperbaric oxygen therapy, it could be used as a treatment protocol for Bisphosphonate induced patients requiring implants. The purpose of this study is to evaluate the effect of HBO therapy on osseointegration of implants supporting mandibular overdenture in bisphosphonate treated osteoporotic patients.

\section{MATERIALS AND METHODS}

\section{Patients' selection}

Sixteen edentulous individuals (eight of them diagnosed osteoporosis and received oral Bisphosphonate drugs more than two years) and the other eight individuals diseased free with mean age of 54.9 years.

Patients were included in the study, provided that they fulfilled the following criteria:

- Free from any other systemic diseases.

- At least four months of healing following tooth extraction prior to implant placement.

- Sufficient bone volume to receive implants with a diameter of $3.75 \mathrm{~mm}$ and a minimum length of $11 \mathrm{~mm}$. This was verified by Cone Beam Computed Tomography to allow for assessment of the alveolar ridge resorption in both vertical, horizontal and buccolingual dimensions.

- Sufficient attached gingiva (keratinized tissues)
Exclusion criteria include: bone grafted or irradiated arches, neurologic or immunologic diseases, microvascular or macrovascular complications, liver dysfunction, anticoagulant therapy and smoking habits. In addition, all patients with contraindications to hyperbaric oxygen therapy such as untreated pneumothorax, upper respiratory infections, high fevers, and emphysema with $\mathrm{CO} 2$, retention, history of thoracic surgery, claustrophobia and convulsions were excluded. The eight systemic free patients were considered as control group while, the eight osteoporotic patients under Bisphosphonate treatment for two years were considered as study group. The study was conducted according to Rules of Helsinki Declaration, and the Faculty's Clinical Research Ethics Committee at Misr University for Science and Technology (MUST) approved the study protocol. Patients were informed about the study protocol and objectives before they signed an informed consent.

\section{Surgical procedures}

Bilateral endosteal implants (Tiologic $®$ Implants, Dentaurum, Ispringen, Germany) were inserted at the location of the former cuspids of the mandible following the standardized twostage submerged surgical protocol suggested by Branemark, which include implant submerging and undisturbed healing of three months. Implants were inserted using a surgical guide for every patient to ensure proper angulations and positioning. The diameter of the final osteotomy done with respect to the surgeon's evaluation of the bone quality to allow for excellent primary implant stability.

\section{Hyperbaric Oxygen Therapy (HBO)}

Patients of control group received no Hyperbaric Oxygen therapy. While, those of study group were managed following a protocol of five sessions of HBO therapy (once/day) ${ }^{[25,26]}$ for five consecutive days at the multi place HBO chamber Fig. (1). Hyperbaric therapy were completed under the supervision of hyperbaric medical specialist at 


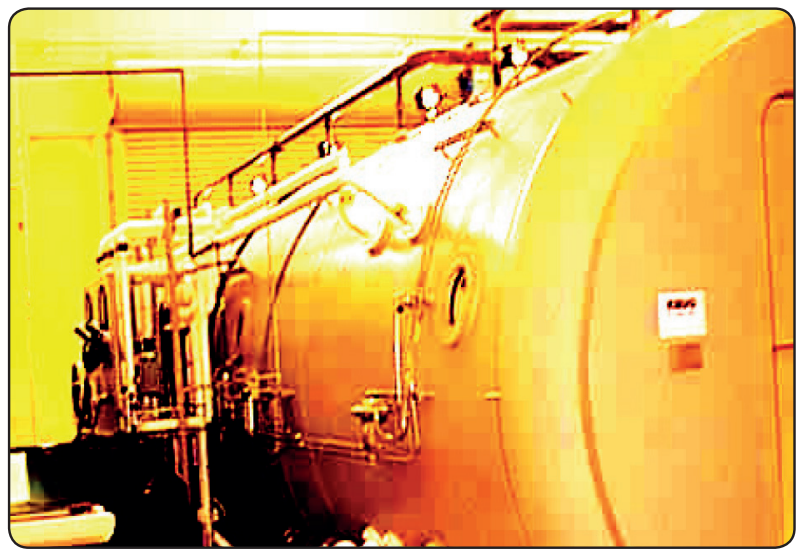

Fig. (1): Multi place HBO chamber

Egyptian Air Force Aero-Medical Institute, Cairo, Egypt. The Hyperbaric therapy session started by compression pressurization where the room pressure was raised from 1 ATA to 2.4 ATA for 15 minutes, followed by oxygen breathing for one hour at 2.4 ATA and finally decompression pressurization for 15 minutes from 2.4 ATA to 1 ATA 24 so each session lasts 90 minutes ${ }^{[27]}$.

\section{Prosthetic procedures}

Patients of both groups received new maxillary and mandibular complete dentures following conventional technique. Two weeks following implant insertion, the patient's existing mandibular dentures were relieved over implant sites and refitted to the mucosa. Three months post-surgically, implants were exposed, and healing abutments were placed. The Locator attachment (Tiologic $®$ Implants, Dentaurum, Ispringen, Germany) used to retain the mandibular dentures for both groups comprises a self-aligning double retention cylinder with retention surfaces on the inner and outer areas (Fig 2,3). A metal body is incorporated in the base of the denture and nylon elements in the negative form of the abutment connect the prostheses with the implant. Pink nylon male inserts were fitted to the locator matrix in this present study. The fitting surface of the new mandibular dentures directly above the implants was relived to provide space for the attachments. For both groups, the outer matrice with the pink inserts were picked up intraorally to the fitting surface of mandibular dentures with cold-cure acrylic resin while patients close in centric occlusion. The new dentures were delivered to the patients with emphasize on oral hygiene instructions, regular recall visits for proper adjustments and replacement of nylon inserts if any worn or fracture occurred.

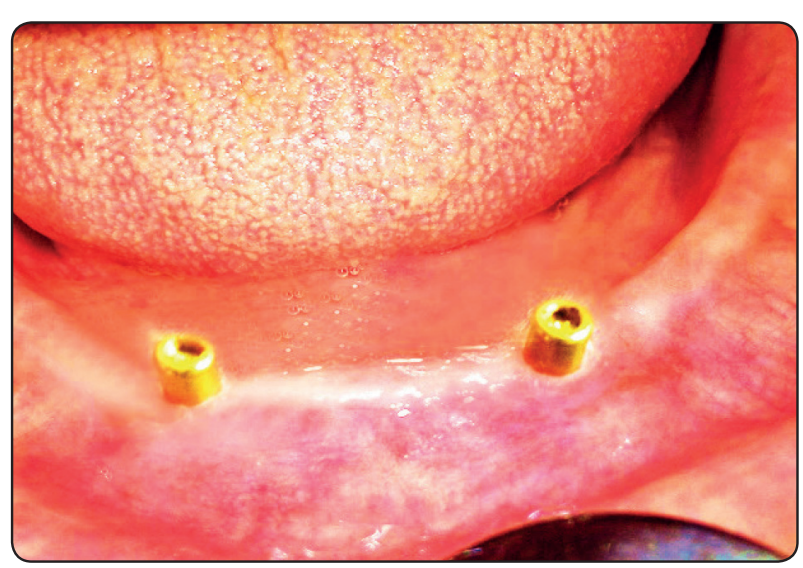

Fig. (2): Locator abutments and overlying locator matrices attached to the implants intra-orally

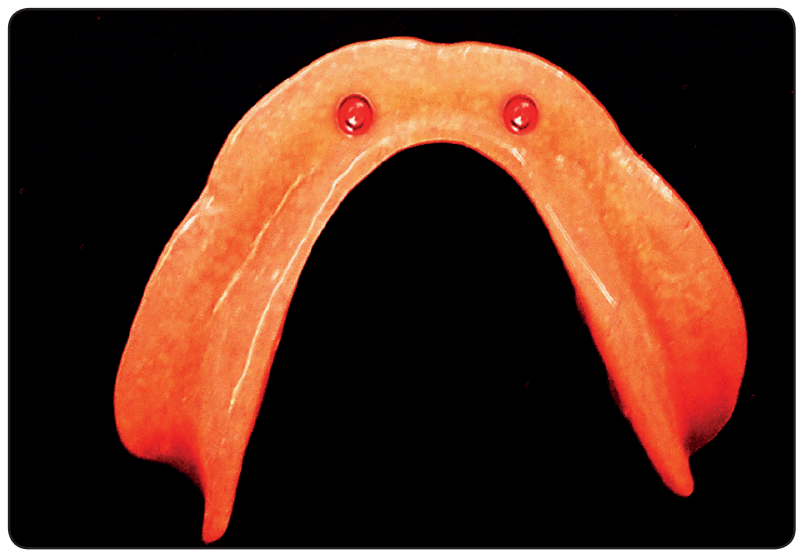

Fig. (3): Locator retained mandibular overdentures

\section{Radiographic assessment}

Patients were recalled at time ofinsertion, six and twelve after denture insertion for follow-up. At these intervals, patients were returned for assessment of implants, prosthesis' function and standardized 
evaluation of their oral health. Cone Beam Computed Tomography (CBCT) was used to evaluate periimplant bone height and bone density. The acquired and reconstructed three-dimensional volume images were exported and saved as DICOM-files (Digital Imaging and Communications in Medicine) on a compact discs and viewed on personal computer. For image analysis, software (OnDemand3D CD Viewer) was used for assessment of peri-implant bone height and density.

\section{Assessment of peri-implant bone height}

Mesial and distal marginal bone height were calculated from the reconstructed corrected sagittal views by drawing a line parallel to the implant serration extending from the marginal bone to the apical end of the implant. By the same way, buccal and lingual marginal bone height was measured by using cross-sectional views. Average readings of the four sides at each interval were calculated and tabulated for statistical analysis Fig. (4).

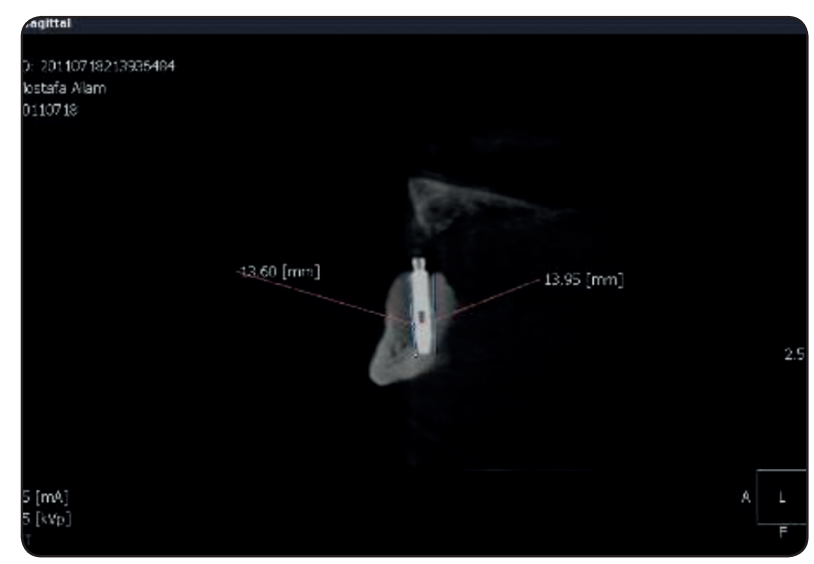

Fig. (4):peri-implant bone height measurements using CBCT

\section{Assessment of peri-implant bone density}

The density measurements were performed by calculating the Hounsfield units (HU) $1 \mathrm{~mm}$ away from the surface of each implant at all buccal and lingual sides (cross sectional views) and mesial and distal sides (corrected sagittal views). Average readings of the four sides were calculated to indicate

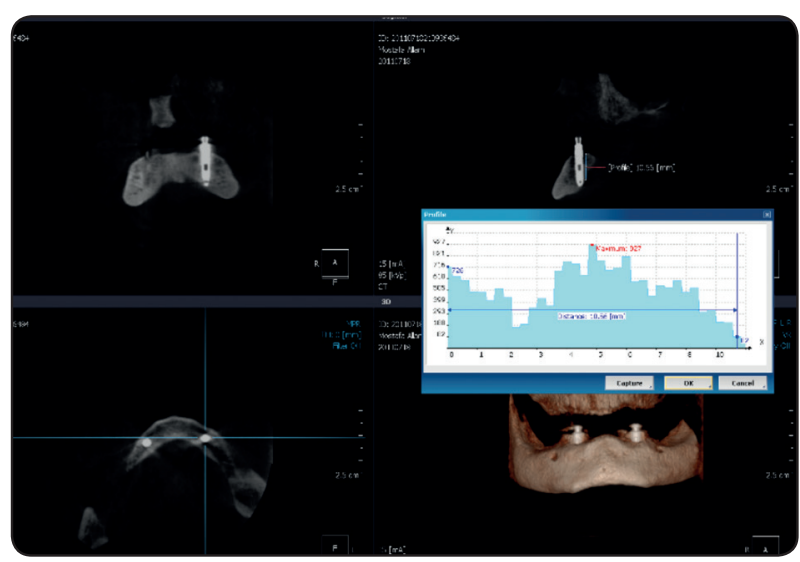

Fig. (5): Measurement of bone density

the density of the bone engaged with the threads of each implant. Results at each interval were tabulated for statistical analysis Fig.(5).

\section{Statistical analysis}

The statistical analysis of data was performed using Excel program and SPSS program (Statistical Package for Social Science) version 22.0. OneSample Kolmogorov-Smirnov Test was used to diagnose normality of data distribution of all variables. The data was parametric and normally distributed and were presented using mean \pm standard deviation. Between-groups comparisons for marginal bone height and bone density were performed using student t-test. Repeated measure ANOVA followed by LSD was used to detect significant differences between observation times. Kaplan-Meyer analysis was used for evaluation of implant survival rates and Log rank test was used to compare survival between groups. P-values $<0.05$ were considered to be significant.

\section{RESULTS}

Patients of both groups completed the followup examination visits and showed success of the implants resulted in $100 \%$ survival rate following Kaplan-Meyer analysis for survival rates (Fig. 6). 


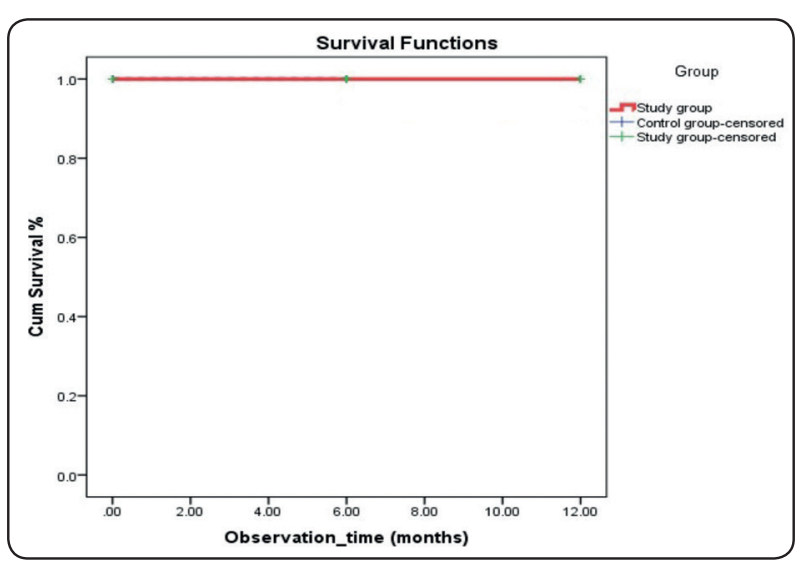

Fig. 6: Kaplan-Meyer survival analysis for both groups.

\section{Peri-implant bone height:}

Table (1) shows significant difference in periimplant bone loss for both groups during the followup periods. There was a significant difference in periimplant bone loss between groups at (T6) and (T12). Study group recorded lower significant differences in peri-implant bone loss than control group at T6 and T12 ( $\mathrm{p}=0.00$ and 0.001 respectively). For both control and study groups, there was a significant difference in peri-implant bone loss between the follow-up periods ( $\mathrm{p}=0.03$ and 0.05 respectively).

TABLE (1) Comparison between the deference of peri-implant bone height in $\mathrm{mm}$ for both groups at T6, and T12.

\begin{tabular}{|c|c|c|c|}
\hline & $\begin{array}{c}\text { Control } \\
\text { group } \\
\mathrm{X} \pm \mathrm{SD}\end{array}$ & $\begin{array}{c}\text { Study } \\
\text { group } \\
\mathrm{X} \pm \mathrm{SD}\end{array}$ & $\begin{array}{c}\text { Independent } \\
\text { samples t-test } \\
(\mathrm{p} \text { value) }\end{array}$ \\
\hline $\begin{array}{c}6 \text { months after } \\
\text { insertion (T6) }\end{array}$ & $0.82 \pm 0.21$ & $0.65 \pm 0.19$ & $0.00^{*}$ \\
\hline $\begin{array}{l}12 \text { months after } \\
\text { insertion (T12) }\end{array}$ & $0.96 \pm 0.23$ & $0.87 \pm 0.16$ & $0.001^{*}$ \\
\hline $\begin{array}{c}\text { Paired sample } \\
\text { t-test (p value) }\end{array}$ & $0.03^{*}$ & $0.05^{*}$ & \\
\hline
\end{tabular}

$X ;$ mean.SD; standard deviation. * Significant difference at 0.05

\section{Peri-implant bone density}

Table 2 shows the bone density (in HU) for both groups at T0, T6 and T12. There was a significant difference in bone density between both groups during all follow-up periods. Study group was significantly higher than control group regarding the peri-implant bone density at different followup periods ( $\mathrm{p}=010,0.00$ and 0.01 respectively). For both control and study groups, there was a significant difference in bone density between the follow-up periods ( $\mathrm{p}=0.02$ and 0.00 respectively).

TABLE (2) Comparison of bone density (in HU) for both groups at $\mathrm{T}(0), \mathrm{T}(6)$ and $\mathrm{T}(12)$.

\begin{tabular}{|c|c|c|c|}
\hline & $\begin{array}{c}\text { Control } \\
\text { group } \\
\mathrm{X} \pm \mathrm{SD}\end{array}$ & $\begin{array}{c}\text { Study } \\
\text { group } \\
\mathrm{X} \pm \mathrm{SD}\end{array}$ & $\begin{array}{c}\text { Independent } \\
\text { samples } \\
\mathrm{t} \text {-test } \\
\text { (p value) }\end{array}$ \\
\hline $\begin{array}{c}\text { At time of } \\
\text { insertion (T0) }\end{array}$ & $\begin{array}{c}911.63 \pm \\
82.19\end{array}$ & $\begin{array}{c}1036.21 \pm \\
33.08\end{array}$ & $0.01^{*}$ \\
\hline $\begin{array}{c}\text { 6 months after } \\
\text { insertion (T6) }\end{array}$ & $\begin{array}{c}1032.61 \pm \\
69.57\end{array}$ & $\begin{array}{c}1068.33 \pm \\
32.30\end{array}$ & $0.00^{*}$ \\
\hline $\begin{array}{c}12 \text { months after } \\
\text { insertion (T12) }\end{array}$ & $\begin{array}{c}1093.83 \pm \\
91.17\end{array}$ & $\begin{array}{c}1110.00 \pm \\
18.08\end{array}$ & $0.01^{*}$ \\
\hline $\begin{array}{c}\text { Repeated } \\
\text { measures }\end{array}$ & $0.02^{*}$ & $0.00^{*}$ & \\
ANOVA (p value) & & & \\
\hline
\end{tabular}

$X$; mean.SD; standard deviation.

* significant difference at .05

\section{DISCUSSION}

Very few studies have been conducted to analyze the effects of HBO therapy on success rate of osteoporotic patients received Bisphosphonate drugs ${ }^{[28,29]}$.

The beneficial role of $\mathrm{HBO}$ in the treatment of various human pathologies either alone or in combination with other therapies have reported in few studies ${ }^{[2829]}$. 
The achieved $100 \%$ survival rate observed in this study were expected due to the selection criteria and increased cellularity, vascularity and enhanced soft tissue and bone healing and regeneration after hyperbaric oxygen therapy ${ }^{[30,31]}$. Five consecutive HBO sessions used in this study was reported in a study aimed to aid in the postoperative stability of orthognathic surgical corrections in patients with severe dentofacial deformities ${ }^{[32]}$.and in a study conducted to evaluate the effect of hyperbaric oxygen on osseointegration around dental implant in uncontrolled diabetic patients ${ }^{[33]}$. The mean peri-implant bone loss in study group (osteoporotic patients under Bisphosphonate therapy who receiving $\mathrm{HBO}$ therapy) was $(0.87 \pm 0.16 \mathrm{~mm})$ which remain within the normal range of values reported in literatures (1.2 $\mathrm{mm}$ in the first year) ${ }^{[33,34]}$.

However, the mean peri-implant bone loss in control group (systemic free patients) was $(0.96 \pm 0.23$ $\mathrm{mm}$ ) which is less than this value. In the results of this study the peri-implant bone loss during the follow-up periods was significantly less in the study group which received HBO therapy. This might be attributed to the physiologic effects of $\mathrm{HBO}$ on the study group which includes improved oxygenation, vasoconstriction, increased antimicrobial activity, bactericidal and bacteriostatic effect and modulation of inflammation. Blood and tissue oxygen tensions were documented to remain elevated for over an hour following a single $\mathrm{HBO}$ treatment in an experimental rat wound model ${ }^{[35]}$. The increase in oxygen tension promotes collagen and adenosinetriphosphate (ATP) synthesis, capillary in growth, osteoblastic and osteoclastic activity and has a triggering role in bone remodeling ${ }^{[36]}$.

There is a correlation between the high level of oxygen tension and elevated osteoblastic and osteoclastic activity ${ }^{[36]}$. The increase in oxygen tension causes cellular differentiation to osseous tissue, whereas decreased oxygen tension results in cartilage formation. The results of peri-implant bone height in this study agree with the study of Nilsson et al. who proved that HBO treatment causes a significant increase in bone formation ${ }^{[36]}$. It also agrees with the studies of Sawai et al. ${ }^{[37]}$, who showed that there is an acceleration in bone healing and an increase in the amount of new bone formation with HBO therapy. The authors found that bone density in both groups are significantly increased after the surgery and during the first year of loading with high levels in the HBO group. The increased bone density with advance of time in both groups may reflect a positive response to the applied forces within the physiologic limit and adaptive capacity. Proper distribution of the load falling on the implants might have enhanced the structural orientation of bone trabeculae and hence increased the bone density around the implants ${ }^{[38]}$. The increased bone density in study group may be due to osteoporosis treatment by Bisphosphonate drugs which characterized by high bone mass and, with a consequent increase in bone hardness causes enhancement of bone-to-implant contact (BIC) and bone thickness. Also, as a result of hyperbaric therapy, Similarly, Johnson, et al. in $1999^{[12]}$ and Granstorm et al. in 2006 reported that Hyperbaric oxygen (HBO) therapy improve the success of osseointegration, as it improves bone maturation ${ }^{[13]}$. Similarly, several studies reported improving osteogenesis, bone remodeling and healing, which result in more bone formation ${ }^{[34,35,36]}$. In addition, the increased bone density after HBO in osteoporotic patients is in line with Elsyad, et. al. in 2012 who studied new surgical template with a handpiece positioner for use during flapless placement of four dental implants to retain a mandibular overdenture and reported that, there is more bone formation ${ }^{[37]}$.

Our results revealed that, there is positive effect of HBO treatment agree with the study of Shaheen and El-Talawy in 2016 who concluded that, hyperbaric oxygen therapy is valuable and effective treatment as it associated with increased implant survival rate and bone density ${ }^{[31]}$. 


\section{REFRENCES}

1. Eastell R, O’Neill T, Hofbauer L, et al. Postmenopausal osteoporosis. Nat Rev Dis Primers 2016; 2: 1e16.

2. Kasper MJ, Peterson GE, Allegrante JP. The need for comprehensive educational osteoporosis prevention programs for young women: Results from a second osteoporosis prevention survey. Arthritis Care Res. 2001; 45:28-34.

3. Pietschmann, P., Mechtcheriakova, D., Meshcheryakova, A., Föger-Samwald, U., Ellinger, I. Immunology of osteoporosis: a mini-review. Gerontology 2016; 62 (2), $128-137$.

4. Moghadam-Kia S, Werth VP. Prevention and treatment of systemic glucoco- rticosteroid side effects. Int J Dermatol 2010; 49: 239-248.

5. McLeod NMH, Patel P, Kusanale A et al. Bisphosphonate osteonecrosis of the jaw: a literature review of UK policies versus international policies on the management of bisphosphonate osteonecrosis of the jaw. Br J Oral Maxillofac Surg 2011; 49: 335-342.

6. Filleul O, Crompot E, Saussez S. Bisphosphonate-induced osteonecrosis of the jaw: a review of 2,400 patient cases. $\mathrm{J}$ Cancer Res Clin Oncol 2010;136:1117-1124.

7. Almubarak H, Jones A, Chaisuparat $\mathrm{R}$ et al. Zolendronic Acid directly suppresses cell proliferation and induces apoptosis in highly tumorigenic prostate and breast cancers. J Carcinog 2011;10: 2.

8. Di Salvatore M, Orlandi A, Babala C et al. Anti-tumour and anti-angiogenetic effects of zolendronic acid on human non-small cell lung cancer line. Cell Prolif 2011; 44: 139-146.

9. Tepos E, Croucher Pl, Garcia- Sanz R et al. The use of bisphosphonates in multiple myeloma: recommendations of an expert panel on behalf of the European Myeloma Network. Ann Oncol 2009; 20: 1303-1317.

10. Zarb GA. The edentulous milieu. J Prosthet Dent 1983; 49: 825-831.

11. Elsyad MA, Ashmawy TM, Faramawy AG. The influence of resilient liner and clip attachments for bar-implant retained mandibular overdentures on opposing maxillary ridge. A 5-year randomised clinical trial. J Oral Rehabil. 2014;41(1):69-77.

12. Johnsson AA, Sawaii T, Jacobson $M$ et al. A histomorphometric study of bone reactions to titanium implants in irradiated bone and the effect of hyperbaric oxygen treatment. Int J Oral Maxillofac Implants 1999; 14: 699-706.

13. Granstorm G. Placement of dental implants in irradiated bone: the case using hyperbaric oxygen. J Oral Maxillofac Surg 2006; 64: 812-818.

14. Almazrooa SA, Woo S. Bisphosphonate and nonbisphosphonate associated osteonecrosis of the jaw. J Am Dent Assoc 2009; 140: 864-875.

15. Orhan K, Bayindir H, Aksoy S et al. Numb chin syndrome as a manifestation of possible breast cancer metastasis around dental implants. J Craniofac Surg 2011; 22: 942-945.

16. Marx RE. Oral and Intravenous Bisphosphonate-Induced Osteonecrosis of the Jaws. History, Etiology, Prevention and Treatment. Chicago: Quintessence Publishing Co Inc, 2007: pp84-86.

17. Kim RH, Lee RS, William D. Bisphosphonates induce senescence in normal human oral keratinocytes. J Dent Res 2011; 90: 810-816

18. Aguire J1, Altman MK, Vanegas SM et al. Effects of alendronate on bone healing after tooth extraction in rats. Oral Dis 2010; 16: 674-685.

19. Wehrhan F, Stockman P, Nkenke E et al. Differential impairment of vascularization and angiogenesis in bisphosphonateassociated osteonecrosis of the jawrelated mucoperiosteal tissue. Oral Surg Oral Med Oral Pathol Endodont 2011; 112: 216-221

20. Hokugo A, Christensen R, Chung EM et al. Increased prevalence of bisphosphonate related osteonecrosis of the jaw with vitamin deficiency in rats. J Bone Miner Res 2010; 25: 1337-1349.

21. Junquera L, Gallego L. Non-exposed bisphosphonaterelated osteonecrosis of the jaws: another clinical variant? J Oral Maxillofacial Surgery 2008; 66: 1516.

22. Hutchinson M, O’ Ryan F, Chavez V. Radiographic findings in bisphosphonate treated patients with stage 0 disease in the absence of bone exposure. J Oral Maxillofac Surg 2010; 68: 2232-2240.

23. Hossam M, Sameh M. Effect of HBO on the sealing ability of different restorative materials. Ain Shams den. J. 2007; 127-137.

24. Hossam M and Ola A. Effect of HBO on the tensile bond strength of repaired composite resin under different dentin bonding agents. Egyptian den. J 2009;55: 2685-2690. 
25. Rizk F. and Shaheen N. Hyperbaric Oxygen Therapy for Promoting Osseointegration Around Dental Implants in Heavy Smokers. Egyptian dental Journal. 2011;57(3):23712380 .

26. Eid HS, W. ES, . The effect of hyperbaric oxygen therapy on improving bony stability in LeFort I maxillary advancement. UHM 2011;38:215-224.

27. Junquera L, Gallego L. Non exposed bisphosphonaterelated osteonecrosis of the jaws: another clinical variant? J Oral Maxillofac Surg 2008; 66: 1516.

28. Hutchinson M, O'Ryan F, Chavez V. Radiographic findings in bisphosphonatetreated patients with stage 0 disease in the absence of bone exposure. J Oral Maxillofac Surg 2010; 68: 2232-2240.

29. Chen X, Matsui Y, Ohno K, Michi K. Histomorphometric evaluation of the effect of hyperbaric oxygen treatment on healing around hydroxyapatite implants in irradiated rat bone. The International journal of oral \& maxillofacial implants. 1999;14(1):61-68.

30. Nooh N. Dental implant survival in irradiated oral cancer patients: a systematic review of the literature. The International journal of oral \& maxillofacial implants. 2013;28(5):1233-1242.

31. Turkyilmaz I. One-year clinical outcome of dental implants placed in patients with type 2 diabetes mellitus: a case series. Implant Dent. 2010;19(4):323-329
32. Nasser H. Shaheen* and Dina B. El Talawy; effect of HBO therapy on marginal bone heigh around implants used to retain mandibular over dentres in uncontrolled diabetic patients Eg. d. 2016; Vol. 62, No. 2

33- Goodacre CJ, Bernal G, Rungcharassaeng K, Kan JYK. Clinical complications with implants and implant prostheses. J Prosthet Dent 2003; 90:121-132.

34- Rollins MD, Gibson JJ, Hunt TK, et al. Wound oxygen levels during hyperbaric oxygen treatment in healing wounds. Undersea Hyperb Med 2006; 33:17-25.

35- Tibbles PM, Edelsberg JS. Hyperbaric-oxygen therapy. N Engl J Med 1996; 334: 1642-1648.

36. Sawai T, Niimi A, Johansson CB, Sennerby L, Ozeki K, Takahashi H, Alberktsson T, Ueda M. The effect of hyperbaric oxygen treatment on bone tissue reactions to c.p. titanium implants placed in free autogenous bone grafts. A histomorphometric study in the rabbit mandible. Clin Oral Implants Res 1998; 9: 384-397.

37. Baker J, Goodkind RJ. Immediate placement and implant loading for expedited patient care; a patient report. Int J Oral Maxillofac Implants 2002; 17: 587.

38. Elsyad MA. A new surgical template with a handpiece positioner for use during flapless placement of four dental implants to retain a mandibular overdenture. J Prosthodont. 2012;21(7):573-577. 